\title{
UM CÃO ANDALUZCOMO IMAGEM DO SURREALISMO E DO INCONSCIENTE FREUDIANO
}

\author{
Djulia Justen ${ }^{1}$
}

\section{Sobre o questionamento da visão ${ }^{2}$ no movimento surrealista}

Desde os gregos até os modernos franceses, a visão era tida como sentido superior para obter conhecimento. Era na visão que a racionalidade humana se compreendia. A partir deste sentido, reconhecido como o mais nobre de todos, onde era possível encontrar verdades claras e objetivas. O pensamento ocidental, principalmente o cartesianismo e o iluminismo, era baseado no entendimento racional, de que todo o conhecimento tinha que passar pela razão e que a visão era o sentido mais adequado, dentre os outros, para conseguir conhecimento. Este apego ao sentido racional da visão foi chamado de iluminismo e passou a ser questionado em estudos de arte e filosofia na França do século 20.

O questionamento mais violento da visão como senso mais nobre é impulsionado pela experiência visual das duas grandes guerras mundiais. Diversos estudos de várias áreas de conhecimento trouxeram, cada um ao seu modo, este questionamento. Neste sentido, podemos incluir o movimento surrealista que, assim como Georges Bataille, trouxe uma interrogação violenta sobre a visão como aponta Martin Jay em Downcast eyes: The denigration of vision in twentieth-century french thought. "The complicated responses of Georges Bataille and the Surrealists will provide an avenue of entry into the new, more violent interrogation of vision after war."3

Partindo deste contexto, os surrealistas encarnam uma postura que repudia a razão, a busca por verdades claras e objetivas, o senso lógico ao perceber o mundo, e adotam a violência e os movimentos inconscientes como integrantes do ser e da vida cotidiana. É com movimentos inconscientes da mente trazidos à tona pela arte surrealista, possíveis de notar nas práticas surrealistas e no filme que será analisado neste artigo, que percebo o

\footnotetext{
1 Djulia Justen é mestranda em teoria literária pelo Programa de Pós-Graduação em Literatura pela Universidade Federal de Santa Catarina (UFSC), membro do Núcleo de Estudos Benjaminianos (NEBEN) e participante do curso de formação em psicanálise pela Maiêutica Florianópolis - Instituição Psicanalítica. Contato:djuliajusten@gmail.com

2 A questão sobre o questionamento da visão foi discutida no ensaio "Olho como forma de pensamento". Nesse artigo, estudei a narrativa de História do olho de Georges Bataille como forma de questionamento do senso mais nobre, além de outras ponderações sobre a imagem do olho nos movimentos de erotismo e transgressão. Disponível em: http://www.desenredos.com.br/6art djulia 180.html.

3 JAY, Martin. "The disenchantment of the eye: Bataille and the Surrealists" in Downcast Eyes: the denigration of vision in twentieth century. 1993, p. 212
} 
questionamento da visão pelos surrealistas. Este movimento artístico busca dar lugar ao pensamento inconsciente, às livres associações que nos levam de imagem a imagem.

É na metáfora do olho que se encontra todo o apego à razão, à racionalidade e à procura de conhecimento verdadeiro, claro e objetivo. E é na metáfora do olho que também é possível encontrar o questionamento da visão como sentido da razão, toda a revolta e violência contra este sentido. $\mathrm{Na}$ arte surrealista é possível perceber diversas manifestações que englobam uma iconografia ocular, onde várias referências ao olho e ao questionamento da visão podem ser notadas. No quadro Ambiguous Figures, de Max Ernst, corpos geométricos e cabeças transparentes nos encaram com óculos de mergulho. $\mathrm{Na}$ colagem de Man Ray, Object to be destroyed, um olho recortado da fotografia de uma amante foi hasteado no contador de tempos de um metrônomo. Na pintura The lugubrious game, Salvador Dali invoca um grande olho angustiado do céu e o quadro está repleto de cenas de enucleação e olhos tampados. A instalação de Alberto Giacometti, Suspended Ball, nos lembra a cena inicial de Um cão andalur: uma imensa bola de concreto fendida, sustentada por uma gaiola, está suspensa sobre uma meia lua. Estes exemplos nos mostram a violência da arte surrealista com relação ao questionamento da visão. Sintetiza Jay:

\footnotetext{
The eye was, in fact, a central image in more than its cinema, and indeed can be discerned in much twentieth-century visual art. Antecipated by Odilon Redon's haunting images of single eyes as ballons, flowers, or Cyclops staring toward heaven, artists like Chirico, Ernst, Dali, Man Ray and Magritte developed a rich ocular iconography.
}

Percebo que o movimento surrealista contrapõe-se à visão por ser o sentido que é a imagem da razão. É contra a racionalidade, a objetividade, este sistema que divide, que separa a razão e a loucura, o bem e o mal, o desejo e a vontade, a verdade e a mentira, o sentido lógico e o sentido não compreensível pelos olhos racionais que o surrealismo se contrapõe. Uma revolta que se formou e se consolidou ainda mais pela experiência da guerra. Os surrealistas foram mais afetados pelas visões da guerra que Georges Bataille, pois eles realmente tinham experimentado este horror de perto, estiveram em combate por obrigação. Esta vivência da guerra gerou uma revolta amarga contra a racionalidade da civilização e o progressismo que se justificava no combate, revolta que se pronunciava tanto na arte surrealista quanto na aderência a movimentos políticos pelos integrantes do grupo em décadas posteriores.

\footnotetext{
${ }^{4}$ Idem p. 259
} 
Breton, Eluard, Aragon, Péret, Soupault were profoundly affected by war. They had fought in it by obligation and under constrained. They emerged from it disgusted; henceforth they wanted nothing in common with a civilization that had lost its justification, and their radical nihilism extended not only to art but to all its manifestations. ${ }^{5}$

Neste sentido das divisões operadas pela superioridade da visão como sentido da racionalidade, trago Jacqueline Chénieux-Gendron para delinear o panorama do questionamento trazido pelo movimento surrealista. Aponta Gendron:

O surrealismo, desde os anos de fundação, na França, em 1919, responde com revolta a esses jogos de divisão. Tais divisões, percebe-as ele com uma lucidez e violência aguçadas pelo desespero e pela ausência de razões para viver nesses anos que vêm depois da guerra. ${ }^{6}$

$\mathrm{Na}$ introdução do livro $O$ Surrealismo, Gendron organiza o surrealismo nos movimentos do interdito e do sentido, movimentos aos quais o surrealismo se contrapõe. No interdito, se colocam barreiras, limites, divisões culturais que separam a verdade e a mentira, a razão e a loucura. Interditos que não apenas dividem, mas que também se colocam como relações de hierarquia: a razão acima da loucura, a verdade como legítima à mentira, o certo como superior ao errado que se impõe na fala, que se comede na racionalidade. "Esses interditos, de fato, assediam fortemente a tomada de palavra. E a isso se acrescenta o dever de só dizer o que é razoável, e de conformidade com os modos codificados da "não loucura'."7

$\mathrm{Na}$ ideia do sentido propõe-se o senso racional, aquilo que se desenvolve a partir da razão da mente, em que tudo só pode ser conhecido pelo sentido lógico, como se houvesse apenas um sentido certo, correto, que é razoável. "Se os séculos que precederam o XIX por vezes decifraram na palavra do louco os sinais da lucidez e as marcas do presságio, era uma maneira de reinvesti-la pela razão, negar-lhe a absoluta diferença."

É contra estes dois movimentos, ligados ao questionamento da visão, pois carregam a racionalidade e a proposição da verdade na civilização, que o surrealismo se contrapõe e lança uma forma surrealista de perceber o mundo. Uma percepção que dá lugar ao ilógico, obsceno e inverossímil, que a razão não conduza mais a vida humana, que o inconsciente possa se manifestar, que a verdade não seja mais a referência na linguagem e na arte. Conceitua Gendron que o surrealismo:

\footnotetext{
${ }^{5}$ NADEAU in JAY, p. 231

6 CHÉNIEUX-GENDRON, Jacqueline. “O interdito e o sentido”. In: O Surrealismo. Tradução: Mário Laranjeira. São Paulo: Martins Fontes, 1992, p. 2

${ }^{7}$ Idem p. 1

${ }^{8} \operatorname{Idem}$ p. 1
} 
[...] pretende abolir a noção de incongruência ou de obscenidade, deixar falar a subconsciência e estimular as diferenças patológicas da linguagem; pretende subverter a busca da verossimilhança na arte por uma formidável aposta no imaginário, apresentado como o poder central do espírito humano, de onde procede toda uma vida-em-poesia. Uma vida em que o inverossímil, o extraordinário, o incôngruo surgissem em profusão, em que a sinceridade não tivesse mais valor de referência absoluta, em que o verdadeiro não fosse mais buscado como tal, mas o viver, viver diferentemente do que se faz na mediocridade do cotidiano, viver à margem dos trilhos que a sociedade nos aponta. ${ }^{9}$

Um destes interditos que o surrealismo se propõe a transgredir é a repressão da violência, da revolta. Violência do ser que foi abolida pela vida civilizada, pelas normas de convivência em sociedade, pela forma coerente e comedida que se deve viver com o outro. Violência que só foi permitida ser descarregada nas guerras. Só na guerra a violência tinha lugar. Para o surrealismo, a violência é assumida em todos os aspectos da vida cotidiana. "O surrealismo propõe reconhecer e assumir a violência humana na revolta em todos os sentidos". ${ }^{10}$

Seguindo essa linha de pensamento do questionamento da visão, em que o surrealismo se contrapõe a este sentido pelo seu apelo racional, é possível perceber que o movimento surrealista nega todo o apego ao sentido lógico, às condutas sociais comedidas e dentro da ordem. O surrealismo rejeita tudo o que já tem significado pronto, já dado. Fazendo um jogo de palavras com a rejeição surrealista, tudo aquilo que fundamenta o sentido não faz ‘sentido’ para os integrantes do movimento. Condensa essa ideia Gendron:

\footnotetext{
O surrealismo é também no mesmo movimento, ou, se quiserem, na sua outra face, uma máquina de negar. Negar tudo aquilo que é implicado pelas divisões e pelos interditos em que se fundamenta a estruturação cultural majoritária: negar as 'ordens' já prontas, negar a pertinência dos códigos (sociais, mas também estilísticos, lingüísticos e mesmo lógicos). Tudo o que organiza o sentido (direcional das coisas, no espaço e no tempo), toda taxinomia, particularmente, e toda evidenciação de significação para nós, são assim suspeitos aos olhos surrealistas. ${ }^{11}$
}

Mas recusando todos os sentidos lógicos e prontos, se revoltando contra os interditos que delimitam, dividem e hierarquizam, que sentido os surrealistas nos propõem? “Trata-se primeiro de recusar os sentidos já prontos, já feitos, ou de criar condições da epifania de um sentido novo? As duas intenções ao mesmo tempo, sendo uma a outra face da segunda." ${ }^{12}$ Mais adiante veremos que essa recusa pelo sentido racional e lógico levará os surrealistas a trazerem à tona o que não é regido pela razão, o inconsciente, e de que maneira os surrealistas conseguiram trazer o movimento inconsciente para arte.

\footnotetext{
${ }^{9}$ Idem p. 2

${ }^{10}$ Idem, p.3.

${ }^{11}$ Idem, p.5.

12 Idem, p.5.
} 
Para complementar as considerações sobre a que o movimento surrealista se contrapõe e se propõe, trago a leitura de Walter Benjamin ${ }^{13}$. O autor escreve o ensaio "O Surrealismo: o último instantâneo da inteligência européia" a partir do ponto de vista onde se encontra. Como já sabemos, o movimento surrealista nasceu em 1919 e se desenvolveu na França. A data da conclusão do artigo é de 1929, ainda a primeira fase do surrealismo antes que o movimento se envolvesse com disputas políticas. Benjamin constrói seu artigo a partir das suas observações estando longe, na Alemanha. Foi uma forma de poder compreender as energias do movimento. "O observador alemão não está situado na fonte. É a sua oportunidade. Ele está situado no vale. É capaz de avaliar as energias do movimento." ${ }^{14} \mathrm{E}$ a esta distância, ele pode perceber que o movimento surrealista procurava dissolver as barreiras do interdito e do sentido, as fronteiras que dividiam o sono e a vigília, a razão e o delírio. Na busca por essa dissolução, como correspondente contrário à razão, era o mundo dos sonhos onde os surrealistas se refugiavam, onde o sentido lógico não tinha lugar, onde o sentido óbvio ficava para trás e permitia a junção de som e imagem, de imagem e linguagem. É na dissolução dos interditos e sentidos, proporcionado pelo mundo onírico, que o surrealismo se apropriava, que se aproximavam ainda mais da imagem e da linguagem.

\begin{abstract}
Mas no início, quando irrompeu sobre os criadores sob a forma de uma vaga inspiradora de sonhos, ele parecia algo integral, definitivo, absoluto. Tudo o que tocava se integrava nele. A vida só parecia digna de ser vivida quando se dissolvia a fronteira entre sono e a vigília, permitindo a passagem em massa de figuras ondulantes, e a linguagem só parecia autêntica quando o som e a imagem, a imagem e o som, se interpenetravam, com exatidão automática, de forma tão feliz que não sobrava a mínima fresta para inserir a pequena moeda a que chamamos de 'sentido'. A imagem e a linguagem passam na frente. ${ }^{15}$
\end{abstract}

Para encontrar este mundo onde som e imagem e imagem e som se interpenetram e onde as barreiras morais e lógicas ficassem para trás foram usados como artifícios as drogas e a hipnose. A utilização destes foi apenas uma maneira inicial de se abalar o interdito e o sentido, para que essa barreira moral que nos contorna fosse abolida de alguma forma. Mas depois de um tempo a utilização dessas práticas alucinógenas não é mais tão necessária assim: "E essas experiências não se limitam de modo algum ao sonho ao haxixe e ao ópio. É um grande erro supor que só podemos conhecer das experiências surrealistas os êxtases

\footnotetext{
13 Outra consideração de Benjamin, como no caso da iluminação profana, vai ser citada mais adiante no tema sobre jogos surrealistas como aprofundamento da noção de acaso objetivo.

${ }^{14}$ Idem, p. 21.

15 BENJAMIN, Walter. "O Surrealismo: o último instantâneo da inteligência européia” In: Magia e Técnica, Arte e Política. São Paulo: Brasiliense, 1994, p. 22.
} 
religiosos ou os êxtases produzidos pela droga." ${ }_{16}$ Quando o pensamento se liberta da sua lógica racional e se permite às livres associações, à percepção das coisas, da atmosfera do acaso; quando já estamos preparados para permitir que o inconsciente se perceba e se manifeste, aí então alucinógenos não são mais essenciais. "O homem que lê, que pensa, que espera, que se dedica à flanerie, pertence, do mesmo modo que o fumador de ópio, o sonhador e o ébrio, à galeria dos iluminados. E são os iluminados mais profanos. Para não falar da mais terrível de todas as drogas - nós mesmos - que tomamos quando estamos sós." 17

Posso dizer que aqui se condensa toda a energia da revolta surrealista. Ao promover a dissolução das fronteiras dos interditos culturais e do sentido, ao se revoltar contra a razão cartesiana, ao tentar abolir as barreiras entre o sono e a vigília na busca por sentidos não dados, o surrealismo nos convoca para uma revolução cotidiana, da forma como vemos o mundo. Ao invés de agir pela racionalidade, o surrealismo nos convoca a afastar as barreiras morais e culturais para então perceber as energias da embriaguez do cotidiano. Sintetiza Benjamin: "A proposta surrealista tende ao mesmo fim: mobilizar para a revolução as energias da embriaguez." 18

\section{Questionamento da visão em Um cão andaluz}

Como exemplo do questionamento do senso mais nobre pelo movimento surrealista, trago a cena principal de Um cão andalur: o olho cortado, dilacerado de ponta a ponta por uma navalha. Diferentemente de História do Olho, de Georges Bataille, em que a visão é tirada do seu posto de superioridade por diversas cenas ao longo da narrativa ${ }^{19}$, em Um cão andaluz vemos a violência de um corte profundo, um corte de ponta a ponta do olho e que se mostra em todos os detalhes, sem jogo de imagens, sem cortes, apenas o levantamento das pálpebras e a navalha cortando o olho e a massa gelatinosa e transparente escorrendo. Esta cena desafia nosso próprio sentido da visão, pois traz a percepção surrealista de romper com a ideia de que o cinema só teria que dar um prazer tranquilo a quem vê. Como conseguir assistir a cena de um olho humano sendo cortado sem se arrepiar de horror? E como também não admirar a cena, perceber cada detalhe deste olho

\footnotetext{
${ }^{16}$ Idem, p. 23.

17 Idem, p. 33.

${ }^{18}$ Idem, p. 32.

19 Em Bataille temos o olho que é comparado com órgãos genitais do touro, as livres associações da personagem Simone ligando ao olho qualquer outro tipo de material banal e a cena final do livro que o olho de um padre é arrancado e que passeia por todas as partes do corpo.
} 
que se corta, morto, incapaz de ver? "The slitting of the eye is thus a figure for the rupture of a visual pleasure accompanying experiences of imagistic wholeness." 20

A imagem do olho cortado também carrega a ideia do reconhecimento da violência pelos surrealistas. Violência que não apenas se deixa escoar nos movimentos de guerra, uma violência que é aceita em todos os movimentos humanos. Violência dirigida a esse sentido que, para os surrealistas, não tem nada de nobre ou puro. Um sentido que apenas permite a percepção da violência. "Whatever the source, there can be little doubt that the eye seemed to many Surrealist artists less an object to be revered, less the organ of pure and noble vision, than a target of mutilation and scorn, or a vehicle of its own violence." ${ }^{21}$

Esta cena é uma amostra do humor negro surrealista, uma forma de crítica mordaz com relação à hegemonia da visão como órgão da racionalidade. O corte demonstra tanto a violência reconhecida pelos surrealistas, quanto brinca com as próprias divisões operadas pela racionalidade através de um corte na carne, um corte no senso que é a imagem da racionalidade, da lógica. Uma forma de dissecar essa racionalidade através de um corte direto, sem a frieza da objetividade cartesiana, de violentar o senso mais nobre. "In short, the provocative slitting of the cow/woman's eye in Un chien andalou is a far cry indeed from de serene dissection of the oeil de boeuf in Descartes's Dioptrique." 22

A partir de agora, veremos outra forma surrealista a respeito do questionamento da visão como órgão da racionalidade: a presença do inconsciente na arte surrealista.

\section{A busca pelo inconsciente no movimento surrealista}

Como forma do questionamento da visão como órgão da racionalidade, percebo que os surrealistas apostaram suas fichas em um movimento que pudesse estar livre dos controles da razão, de inibir a atividade da consciência que sempre esbarra na racionalidade. Os surrealistas apostaram no inconsciente, ainda que não o chamassem desta forma como nos estudos freudianos. Podemos perceber essa busca pelo inconsciente na definição do termo surrealismo no Manifesto Surrealista: "Automatismo psíquico pelo qual alguém se propõe a exprimir seja verbalmente, seja por escrito, seja por qualquer outra maneira, o funcionamento real do pensamento. Ditado do pensamento sem ausência de todo controle exercido pela razão, pela moral, fora de qualquer preocupação estética ou moral."” ${ }_{23}$ É aí que podemos perceber essa busca pelo inconsciente, por este pensamento que não é controlado

20 Op. cit. JAY, p. 259.

${ }^{21}$ Idem p. 260

22 Idem p. 261

23 BRETON, 1924, p. 191. 
pela razão nem pela moral, e que é expresso de alguma maneira, seja pela escrita ou pela arte.

Mas mesmo com essa ideia do inconsciente que ressoa na definição do surrealismo dada por Breton, é pouco provável que realmente os surrealistas se basearam nos estudos de Freud no que tange à descoberta do inconsciente (inconsciente que estava coberto, escondido nas nossas mentes e que pelos estudos de Freud é trazido à luz da nossa consciência). Poucos surrealistas tiveram como ler as obras freudianas por uma questão prática: os textos freudianos só passaram a ser traduzidos a partir de 1921, e aos poucos. Ambos, o surrealismo e o desenvolvimento das teorias de Freud, são contemporâneos, início do século 20. Os surrealistas que realmente tiveram contato com os estudos de Freud foram os alemães Max Ernest, Hans Arp e Tristan Tzara que se juntaram ao movimento surrealista francês. Desta forma, ao que essa constatação feita por Gendron indica, Breton não poderia, explicitamente, estar falando do inconsciente freudiano.

As formulações dessa época, as de Aragon, mas principalmente as de Breton, não estão isentas de certa imprudência, na medida em que remetem a um saber psicológico datado - é a evidência - e adquirido de segunda mão (o que é natural no que diz respeito ao pensamento freudiano, cuja obra só é traduzida para o francês a partir de 1921 , e pouco a pouco). ${ }^{24}$

Ainda que não se possa dizer que Breton falava diretamente sobre o inconsciente, não se pode negar que ele tentou trazer à tona o inconsciente através de técnicas ou jogos da produção artística surrealista, procurando deixar de lado o controle racional e moldado pelo sentido, pela obrigação da compreensão racional. Neste sentido, podemos dizer que houve essa busca pelo inconsciente como uma linguagem e que esta se dava num espaço psíquico dos sonhos, onde as pulsões se manifestavam sem os controles da razão. Então, esta linguagem do inconsciente podia se exprimir quando as estruturas da consciência fossem destituídas de seu lugar de guardas da mente.

\footnotetext{
A natureza no discurso que aflora na palavra automática parece ser para Breton a própria voz de 'nossa inconsciência' (Entrée dês médiums). Ele não escreveu nosso inconsciente, e deve-se insistir nessa diferença, assim como na problemática funcional em Aragon. Mas, afinal nos termos fluxo, pensamento falado, ditado (Breton), matéria mental (Aragon), nas precauções enunciadas para captar-lhe a onda pura (automatismo psíquico puro), pode-se ler que se tratava da 'própria linguagem do inconsciente', e que essa linguagem 'se formava naquela zona da criatividade psíquica de onde vêm as pulsões instintivas, as imagens primordiais, os sonhos, o que supunha que o inconsciente se manifesta espontaneamente como linguagem, que ele é uma estrutura lingüística, uma linguagem potencial que se realiza logo que as cercas que o mantinham prisioneiro são suprimidas. ${ }^{25}$
}

\footnotetext{
24 Op cit. GENDRON, pp. 62 - 63.
}

25 Idem, p. 63. 
Até aqui pudemos compreender que, ainda que o movimento surrealista não estivesse atualizado com as obras freudianas e com a descoberta do inconsciente, os surrealistas trataram o inconsciente como uma linguagem que pode vir à tona a partir do momento em que as barreiras morais da consciência fossem deixadas de lado. A partir disso, os surrealistas criaram jogos, técnicas para trazer a linguagem do inconsciente para as suas produções artísticas. Este tema é o que veremos a seguir.

\section{Os jogos surrealistas nas imagens de Um cão andaluz}

É através dos jogos surrealistas, dos usos de conceitos próprios, que este movimento pode trazer à tona o inconsciente através da arte. Conceituaremos as quatro técnicas surrealistas: escrita automática, acaso objetivo, teoria da imagem e humor negro. A cada um desses jogos estudados vamos apresentar imagens ${ }^{26}$ destes conceitos no filme.

\section{Escrita automática}

É a escrita automática uma das primeiras técnicas que deu início à produção surrealista. Foi uma atividade elaborada e praticada extensivamente ao longo dos anos de 1919 a 1923, os primemos anos do surrealismo. Alguns chegam a equivaler a escrita automática ao surrealismo, tamanho foi o impulso desta prática para a atividade do movimento. "Terem os surrealistas colocado tantas esperanças no automatismo a ponto de a palavra 'surrealista' ter podido empregar-se em lugar de 'automático' mostra com evidência que a definição da atividade surrealista gira em torno da de automatismo.” ${ }_{27}$ Outro ponto que podemos perceber a importância da escrita automática é na própria definição do surrealismo ${ }^{28}$ como automatismo psíquico, livre de qualquer barreira moral ou estética, o ditado do funcionamento real do pensamento.

A escrita automática consiste numa escrita, num ditado verbal ou até mesmo num grafismo em que se busque, neste movimento, deixar de lado o controle da razão, do gosto estético. Procurar ao máximo deixar a consciência quieta para que outros sentidos, que não

\footnotetext{
26 Seria contraditório de minha parte, após todo este estudo do questionamento da razão trazido pelo movimento surrealista, tentar dar conta de exemplificar todas as imagens do filme. Um posicionamento desta forma não seria condizente com os próprios surrealistas que não se preocupavam em dar os sentidos e explicações das suas obras. Partindo disto, cito as cenas que para mim fazem sentido com relação aos jogos surrealistas estudados e com as características do inconsciente. O leitor está livre para encontrar outras cenas que se referenciem os temas estudados.

27 Op cit. GENDRON, p. 55.

28 Citação na íntegra se encontra no tema anterior deste ensaio.
} 
os lógicos e objetivos, tenham lugar. Para isso, o sujeito que se coloca nessa escrita automática precisa estar livre das perturbações que o liguem ao mundo externo e aos seus interditos morais e culturais, da utilidade e da objetividade. Breton traça os caminhos dessa experiência: "Resolvi obter de mim um monólogo com um fluxo tão rápido quanto possível, sobre o qual o espírito crítico do sujeito não faça levantar nenhum juízo, que não se embarace, consequentemente, com nenhuma reticência." 29

Breton insiste na busca da dissipação do controle da razão e do gosto para que a escrita automática efetivamente encontre o seu fim, o funcionamento real do pensamento.

\footnotetext{
Para que essa escrita seja de fato automática, é necessário que o espírito tenha conseguido colocar-se em condições de desligamento em relação às solicitações do mundo exterior assim como em relação às preocupações individuais da ordem utilitária, sentimental, etc., que passam por ser muito mais da alçada do pensamento oriental do que do pensamento ocidental e supõem da parte dessa tensão, um esforço dos mais persistentes. ${ }^{30}$
}

A escrita automática é o primeiro passo para a produção surrealista. Ao deixar de lado os apelos da razão, do comedimento consigo mesmo diante da escrita, de um juízo superior que se impõe a cada momento em que se tenta exprimir algo, outros sentidos podem ser percebidos, um ritmo, uma palavra, uma imagem arbitrária em si que a escrita automática deu lugar. E até podemos pensar o que seria de outras obras ou mesmo das ideias quando esse julgo racional se deixa do lado de fora. O quanto não seria produzido se não nos ponderássemos tanto pelo juízo racional. "O ponto comum com a aventura da escrita automática está no lado arbitrário (quando se dará ao arbitrário o lugar que lhe compete na formação das obras e das idéias?, diz Breton)." 31

Percebo a escrita automática como a amplitude do questionamento da visão como órgão da razão justamente por deixar de lado a racionalidade, a lógica, o comedimento consciente, os gostos e escolhas estéticas e deixar fluir outra forma de pensamento, outros sentidos que não sejam balizados pela razão. Ou seja, dar lugar a livre associação de pensamento. "É necessário recusar o julgo da lógica que conduz, na vida, a negar o sonho a sua potência perturbadora - note-se que estamos aqui numa perspectiva freudiana - e, na literatura, a esmagar o maravilhoso. A escrita automática oferece uma técnica para tal fim." 32

\footnotetext{
${ }^{29}$ Idem, pp. $56-57$.

${ }^{30}$ Idem, pp. 56 - 57.

${ }^{31}$ Idem, p. 39.

32 Op cit. GENDRON, p. 46
} 
Esta livre associação que é libertada através da escrita automática é também uma técnica psicanalítica ${ }^{33}$ capaz de trazer tensões inconscientes à tona. $\mathrm{O}$ analisando deve procurar dizer tudo o que lhe vier à mente sem deixar se balizar pela lógica e pela racionalidade ou por algo que seja vergonhoso ou doloroso. É a partir dessa liberação das livres associações que o analista pode perceber os afetos, as representações e as lembranças que estão sendo reprimidas. Essa é considerada a principal regra psicanalítica para conhecer o inconsciente, além da interpretação dos sonhos e dos atos falhos. A escrita automática é capaz de trazer as livres associações de pensamentos e de imagens, assim como a livre associação é capaz de permitir que a lógica do inconsciente se manifeste.

No filme Um cão andalur, podemos perceber a escrita automática como a própria forma da produção do roteiro. Nos primeiros dias de Janeiro de 1929, Dalí e Buñuel começaram a escrever o roteiro do filme com base em sonhos que ambos tiveram. Dalí havia sonhado com uma mão de onde saiam formigas, Buñuel com a cena do olho cortado. O nome do filme é tipicamente surrealista: não quer dizer nada, não tem relação com o filme e nem um cão andaluz aparece nele.

As livres associações que a escrita automática libera se apoderam em diversas cenas do filme. A primeira delas é a associação do corte das nuvens na lua com o corte do olho pela navalha. Outra associação aparece na mão com um buraco repleto de formigas. Esta imagem leva a mais duas outras, sequenciais, de uma axila peluda e de um ouriço do mar. Temos a associação de imagens do personagem quando toca o corpo da mulher. Seus olhos se reviram e aparecem formas similares aos glóbulos oculares: os seios e as nádegas da mulher.

\section{Teoria das imagens surrealistas}

O estudo de uma teoria da imagem surrealista se compõe ainda na década de 20. A imagem surrealista acompanha a prática da escrita e do desenho automático, que nos oferece uma profusão de imagens a partir das suas livres associações. Tanto a escrita automática quanto a imagem surrealista fazem eco ao questionamento da visão como órgão da racionalidade, na medida em que a escrita automática exige a dissolução dos controles da razão. Já a teoria da imagem surrealista propõe que os códigos formais de arte sejam abolidos. O artista surrealista Max Morise propõe "a emergência de uma pintura surrealista

\footnotetext{
33 ROUDINESCO, Elizabeth e PLON, Michel. "Regra fundamental" in Dicionário de Psicanálise, Rio de Janeiro: Jorge Zahar, 1998. p. 649.
} 
em que 'as formas e as cores dispensem o objeto, se organizem segundo uma lei que escapa a qualquer premeditação, se faz e se desfaz ao mesmo tempo em que se manifesta". ${ }^{34}$

Como já foi mencionado, a escrita automática, pela sua forma "incontrolável", libera, através das suas associações livres, uma profusão de imagens. Tanto um texto como uma pintura estão repletos de imagens, acarretadas por estas livres associações liberadas na escrita automática. Para os surrealistas, estas imagens liberadas estão longe de regras de composição, da lógica ou do entendimento comedido. Estas imagens são criações de um espírito que se liberta da razão. Nas imagens surrealistas, podemos perceber mundos sobrepostos, distantes, porém aproximados pela imagem. É aí que reside a força da imagem surrealista: quanto mais a imagem estiver carregada por estas analogias imprevistas dos elementos, mais forte será a imagem.

\footnotetext{
A imagem é uma pura criação do espírito. Ela não pode nascer de uma comparação, mas da aproximação de duas realidades mais ou menos distanciadas. Quanto mais as relações entre as duas realidades aproximadas forem distantes e exatas, mais a imagem será forte - maior será a sua potência emotiva e sua qualidade poética. A emoção assim provocada é pura, poeticamente, porque nasceu fora de qualquer imitação de qualquer evocação, de qualquer comparação. ${ }^{35}$
}

Das imagens tipicamente surrealistas deste filme, que condensam sua força por mostrar elementos distintos juntos, temos alguns exemplos: a cena do olho cortado pela navalha e a sua massa gelatinosa escorrendo. Outra imagem é a da mão com um buraco cheio de formigas e que os dois personagens encaram como se fosse um quadro. Também temos a imagem da mariposa na parede que, quando aproximada, traz uma caveira no dorso. Outra cena que nos mostra uma imagem surrealista é a do personagem que, subitamente, encontra no quarto a 'carruagem' dos padres enforcados e do piano coberto de burros moribundos. Todas estas imagens nos apresentam esta característica da imagem surrealista: uma imagem forte por trazer a imprevisibilidade da junção dos elementos e de sua analogia.

\section{Acaso objetivo}

O acaso objetivo começou a ser praticado ainda na década de 20, mas sua teorização só foi concebida depois de 1930. Foi aí que o termo 'acaso objetivo' passou a estar presente nas publicações surrealistas.

\footnotetext{
34 Idem, p.69.

35 REVERDY in GENDRON, p. 72.
} 
Neste procedimento, dois termos são aglutinados para dar sentido a esta atividade. O primeiro deles é o acaso. Conhecemos a definição de acaso de Aristóteles que diz: "causa acidental de efeitos excepcionais ou acessórios com a aparência da finalidade" ${ }^{36}$. Ou seja, acaso é um encontro acidental, sem uma explicação obrigatória e lógica e longe de qualquer finalidade utilitária ou de previsão futura. Esbarrar com um distante conhecido na rua, sem que planejasse um encontro ou que se soubesse do seu trajeto, é encontrar com o acaso. $\mathrm{O}$ segundo termo que remonta esta atividade surrealista é o objetivo. Por ele já nos lembramos de objeto, de algo concreto diante de nós. O acaso objetivo é a junção destas duas ideias, o encontro acidental com algo concreto, um objeto diante de nós, mas que não se limita a isso. E como se não bastasse este encontro acidental com algo, o acaso vai de encontro com algo que temos em nós mesmos, algo que está inconsciente, mas que, de alguma maneira, por manifestação deste acaso, ele aparece como um sinal, uma lembrança. Algo que está no fundo de nós mesmos, mesmo que não saibamos qual é o sinal e qual é a lembrança.

\begin{abstract}
O acaso objetivo seria a forma de manifestação da necessidade exterior que abre caminho no inconsciente humano. Em outras palavras, diante da coincidência (excepcional) entre a necessidade natural e a necessidade humana - do desejo humano e do temor do homem - o acaso pode ser chamado de objetivo visto que tudo se passa então como se a subjetividade (desejante) da pessoa envolvida se projetasse num objeto. ${ }^{37}$
\end{abstract}

A leitura de Walter Benjamin sobre o surrealismo acaba por aprofundar esta noção do acaso objetivo a partir da iluminação profana. Percebo esse aprofundamento do acaso objetivo pela percepção das coisas, dos objetos que o acaso objetivo sugere. Uma inquietação com o simples, com algo que se passaria despercebido por olhos cartesianos. Um acaso que passaria despercebido se não fosse esta percepção do simples, daquilo que inquieta, que é capaz de chocar. Benjamin nos dá a sua percepção de leitor da obra de Breton, Nadja. É a partir da sua leitura do romance que ele aprofunda essa ideia do acaso objetivo como uma iluminação profana, uma percepção das coisas simples que podem nos encontrar; um certo estremecimento com este reconhecimento e um avanço no sentido que acaba de se despertar pela impressão do acaso objetivo.

Quanto ao mais, o livro de Breton é muito apropriado para ilustrar alguns traços fundamentais dessa 'iluminação profana'. Ele escreve Nadja como um 'livre à porte batante', um livro de portas batentes. (Em Moscou, hospedei-me em um hotel cujos quartos eram quase inteiramente ocupados por lamas tibetanos, que tinham ido a Moscou para participar de um congresso de todas as igrejas budistas. Impressionou-me o número de portas que ficavam sempre entreabertas, nos corredores. O que a princípio parecia um simples acaso, acabou por me inquietar. Descobri então que os hóspedes eram membros de

\footnotetext{
36 ARISTOTELES in GENDRON, p. 92.

${ }^{37}$ Idem, pp. 92-93.
} 
uma seita, que tinham feito voto de nunca permanecer em espaços fechados. $\mathrm{O}$ leitor de Nadja pode compreender o choque que senti.) ${ }^{38}$

É com esta iluminação profana do acaso objetivo que podemos perceber como as coisas, os objetos, os acontecimentos podem nos tocar, como podemos perceber a vida cotidiana com outros olhos, como olhos surrealistas, olhos desconfiados com os interditos culturais e morais e os sentidos lógicos, com significados já dados e óbvios. E com a iluminação profana acarretada pelo acaso objetivo, podemos nos dar conta de sentidos que podem despertar o nosso inconsciente. É com olhos surrealistas que podemos perceber o cotidiano sempre nos tocando, sempre nos colocando ao encontro de objetos que nos levam ao nosso inconsciente. Ter olhos surrealistas é estar aberto ao simples, ao pequeno, aquilo que por mais simples pode inquietar e chocar. Benjamin nos convoca a essa postura surrealista através de Breton e Nadja.

O casal Breton e Nadja conseguiu converter, se não em ação, pelo menos em
experiência revolucionária, tudo o que sentimos em tristes viagens de trem (os
trens começam a envelhecer), mas tardes desoladas nos bairros proletariados das
grandes cidades, no primeiro olhar através das janelas molhadas de chuva de
uma nova residência. Os dois fazem explodir as poderosas forças 'atmosféricas'
ocultas nessas coisas. Imaginemos como seria organizada uma vida que se
deixasse determinar num momento decisivo, pela última e mais popular das
canções de rua. ${ }^{39}$

Como encontro do acaso objetivo pelos personagens, cito duas cenas. A primeira delas é a da mulher que encontra uma mão decepada na rua e passa a cutucá-la. Aquela mão descarnada de um corpo tem algo que toca o inconsciente da personagem. É possível perceber isso pelo olhar que ela lança ao objeto, um tanto inquieto, querendo entender. Outra cena é a do encontro da caixa e das roupas, jogadas pela janela em outra cena e que agora é encontrada nas pedras da praia. O casal encontra estes vestígios, os recolhe e depois os devolve ao mar, como se daquele passado que os objetos representam não tivesse mais sentido naquele momento. Este acaso objetivo é o encontro do passado do casal com o presente.

Como iluminação profana, escolho citar a minha ao ver este filme. Iluminação profana que cada um pode ter através dos elementos deste filme e de qualquer outra obra. Desde a primeira vez que assisti Um cão andaluz ele me tocou de alguma forma, a sua descontinuidade, as imagens surrealistas. Para mim, elas queriam me dizer algo, me tocaram de alguma forma que naqueles primeiros momentos ainda não sabia o porquê, mas pressentia a sua força. Esta é a sensação do acaso objetivo. Só depois de perceber o filme com mais cuidado, ao prestar mais atenção nas suas imagens, ao estar mais atenta aos

\footnotetext{
38 BENJAMIN, 1994, p. 24.

${ }^{39}$ Idem, p. 25.
} 
detalhes que podem nos chocar, pude perceber que este filme me levava a outro sentido mais profundo, que é para onde nos leva a iluminação profana. Pude perceber que o filme tratava da linguagem do inconsciente, de trazê-lo à tona através das suas imagens.

\section{Humor negro}

É a partir dos anos 30 que o surrealismo conceitua e inicia a prática do humor negro. A denominação 'humor negro' só veio com o movimento surrealista, ainda que se possa dizer que ele já existia. A concepção teórica do humor negro é retirada das notas de Estética de Hegel, em relação a sua noção de humor subjetivo. Acrescenta-se que o humor negro foi desenvolvido com base nas ideias de Os chistes e sua relação com o inconsciente, de Freud, livro que foi publicado na França em 1930. Foi do humor negro que o surrealismo impregnou seu estado de espírito ao longo do entreguerras.

No humor negro, compreendo a crítica feroz surrealista, uma crítica mordaz carregada da revolta contra a razão da civilização, contra a religião, contra o comedimento racional do ser humano. Nessa crítica ácida, o surrealismo não deixa de dar amostras da sua revolta, da sua aceitação da violência, que é acompanhada por essa crítica no humor negro. “O humor puxa em sentido oposto, se o seu projeto é ferir a representação que fazemos a nós dos acontecimentos e da sua ligação opressiva com o eu - deles oferecendo uma imagem completamente subversiva." ${ }^{40}$

O humor negro é creditado a uma observação do mundo e não é simplesmente uma ironia. Com este é relacionado um valor defensivo das ameaças cotidianas à liberdade humana pelo império da razão. Não é à toa que o humor é relacionado com 'negro'. Nesta cor se condensa todo o poder de revolta surrealista, que após os anos 40 se transformou em disputas políticas. "O humor corrói a representação de mundo.” 41

No filme podemos perceber algumas imagens de humor negro. Uma delas é a cena em que o rapaz puxa duas cordas pelas costas, trazendo um piano de calda com dois burros pestilentos, juntamente com mais dois padres que se enforcam nas cordas puxadas pelo rapaz. Uma carga trazida pelas costas, uma carga que nos oprime: o peso da religião que aos poucos se enforca e que podemos comparar a burros moribundos.

Outro elemento de cena é um crucifixo em forma de raquete que a moça pega para se defender dos ataques do rapaz. Um crucifixo transformado em uma raquete, um objeto tão simples relacionado com o símbolo do cristianismo, signo de uma morte redentora.

40 Op. cit. GENDRON, p. 102.

${ }^{41}$ Idem, p. 102. 
Outra imagem nos apresenta toda a revolta surrealista contida no humor negro: quando um dos personagens está de castigo e o pai lhe dá dois livros para que este segure para intensificar ainda mais o castigo. Estes livros se transformam em revólveres e o personagem atira com muito gosto, com feroz brilho nos olhos. Uma reconhecida atitude surrealista que nos lembra um trecho do Segundo Manifesto Surrealista que diz que um ato surrealista é sair à rua com revólveres em punho e atirar ao acaso. Atirar ao acaso nesta racionalidade comedida que nos oprime. Atirar ao acaso com a ferocidade da crítica do humor negro.

\section{A sensação do estranhamente familiar em Um cão andaluz}

É inegável o estranhamento primeiro que se sente ao assistir Um cão andalu\%. Suas imagens nos desconcertam desde a primeira cena. E logo no começo já nos deparamos com o olho de uma mulher sendo cortado. E a partir daí se sucedem uma profusão de imagens que a princípio parecem desconexas, sem sentido e então atribuímos ao filme o adjetivo 'estranho', justamente porque estamos habituados a considerar como estranho aquilo que não nos é conhecido, aquilo que é novo, o que nos assusta, o que está fora dos padrões do entendimento. Mas, com o conceito freudiano do estranho, podemos perceber que este primeiro estranhamento que sentimos ao ver este filme não condiz com esta noção a que atribuímos o sentido de estranho. Com a noção de Freud sobre o estranho, podemos perceber que este estranhamento que nos toca ao ver as imagens de Um cão andaluz tem a ver com o que nos é conhecido, que nos é íntimo e muito familiar, que reprimimos todos os dias, mas que sempre tenta retornar na forma de uma sensação estranha, que é o nosso desejo inconsciente.

Como comentei, utilizamos comumente a palavra 'estranho' para designar o que é novo, o que pode nos amedrontar. A exclamação "Isto é estranho" sai das nossas bocas quando nos deparamos com algo que não compreendemos, que não nos é conhecido. Para além deste uso cotidiano da palavra estranho, Freud faz um estudo linguístico da palavra heimlich, ou seja, o que é familiar e aquilo que seria o seu contrário: unbeimlich, o que é estranho. Vários significados são atribuídos a esta palavra: aquele que pertence à família, ambiente ou pessoas que nos fazem sentir confortáveis, um lugar ou uma situação receptiva e aconchegante. Mas heimlich também é aquilo que está escondido, o que é ocultado da vista do outro, aquilo que nos é íntimo. Ou seja, heimlich acaba por abarcar seu próprio contrário (unheimlich), aquilo que é re-conhecido a partir do momento que processos 
mentais inconscientes são trazidos à consciência. Neste sentido, o "estranhamente familiar" é aquilo que está às escondidas, não aparece, mas sabemos, por meio de alguma impressão, de que está lá, que nos é conhecido de algum tempo. "Unheimlich é o nome de tudo que deveria ter permanecido secreto e oculto, mas veio à luz." 42

Freud desenvolveu o conceito do "estranhamente familiar" com uma leitura do conto "O homem de areia", de Ernest Theodor Amadeus Hoffman. Neste conto fantástico, o psicanalista analisa que algo foi reprimido na infância, a relação entre o homem de areia - que fere os olhos das crianças que não querem dormir - e a morte do pai do personagem. É no retorno dessa figura do homem de areia que o conto se desencadeia e se finda e de onde surge o sentimento do estranho: algo que é familiar ao personagem, que remete ao que foi reprimido na infância, o desejo de matar o pai. É este o sentido do estranho freudiano. O estranho só se manifesta porque algo foi reprimido, algo inconsciente foi impedido de se fazer consciente, independente da idade e do processo psicológico que o ser esteja inserido.

\begin{abstract}
Se a teoria psicanalítica está certa ao sustentar que todo afeto pertencente a um impulso emocional, qualquer que seja a sua espécie, transforma-se em reprimido, em ansiedade, então, entre os exemplos de coisas assustadoras, deve haver uma categoria em que o elemento que amedronta pode mostrar-se algo reprimido que retorna. Essa categoria de coisas assustadoras construiria então o estranho; e deve ser indiferente a questão a saber se o que é estranho era, em si, originalmente assustador ou se trazia outro afeto. (...) Pode-se compreender por que o uso lingüístico estendeu das heimliche para seu oposto, das unbeimliche; pois esse estranho não é nada de novo ou alheio, porém algo que é familiar e há muito estabelecido na mente, e que somente se alienou desta através do processo de repressão. ${ }^{43}$
\end{abstract}

Agora assim podemos falar que Um cão andaluz é um filme estranho porque suas imagens tocam em algo que nos é muito conhecido, algo que nos é íntimo e que é reprimido todos os dias por causa da necessidade lógica e de racionalidade na nossa vida cotidiana. Reprimimos toda e qualquer manifestação inconsciente, as livres associações, não damos atenção aos atos falhos e aos lapsos de memória, consideramos sonhos como espumas, essas maneiras que o inconsciente tende a se manifestar.

A partir de então, vamos apresentar algumas características do processo inconsciente que podemos continuar a perceber na película.

\title{
Imagens do inconsciente em $U m$ cão andaluz
}

\footnotetext{
42 FREUD, Sigmund. "O estranho" In: História de uma neurose infantil e outros trabalhos. Volume 17. Imago: Rio de Janeiro, 1969, p. 282.

43 Idem, pp. 300-301.
} 
Para podermos falar do inconsciente é preciso notar sua existência. É possível perceber a concretude do inconsciente à medida que nos damos conta de que existem atos e pensamentos que não nos são conhecidos pela consciência. Que existem lapsos, esquecimentos, atos falhos em que a nossa intenção não teve lugar, que algo escapou do conhecimento da consciência. Além de existir em nós pensamentos espontâneos que sua elaboração nos permanece oculta. Resistir ao reconhecimento do inconsciente é acreditar que tudo o que se passa pela mente nos é conhecido, que tudo o que experimentamos, pensamos e dizemos só se apresenta porque temos consciência destes atos psíquicos. "Todos esses atos inconscientes permanecem desconexos e incompreensíveis se insistimos na pretensão de que através da consciência experimentamos tudo o que nos cede em matéria de atos psíquicos, mas se inscrevem numa coerência demonstrável se neles interpolamos atos inconscientes inferidos." ${ }^{44}$ No surrealismo, podemos perceber essa aceitação dos movimentos inconscientes justamente por eles darem atenção ao que não é balizado pela coerência racional da consciência, por eles serem guiados nas suas produções artísticas por algo que não precisa ser consciente para se manifestar.

Freud nos aponta de que forma podemos conhecer o inconsciente, além dos dados que podemos reconhecer após se tornarem conscientes. Para podermos trazer o inconsciente à tona, é necessário que as barreiras morais e racionais, aquelas que procuram a lógica do pensamento, que nos fazem balizar as palavras sejam superadas e que não continuem a reprimir as ideias, ou seja, a resistência. "Isso requer que o analisando supere determinadas resistências, as mesmas que outrora, rejeitando-o do consciente, transformaram um dado material em reprimido." 45 Algo muito condizente com o que acabamos de ver nos jogos surrealistas de produção artística, sempre evitando as resistências de pensamento, abrindo as portas para as livres associações e evitando ao máximo a resistência da lógica da razão. Também é importante lembrar que a repressão evita que um conteúdo inconsciente chegue à consciência, ou seja, tudo que é reprimido é inconsciente, mas nem todo o inconsciente é reprimido. "O inconsciente tem âmbito maior; o reprimido é uma parte do inconsciente." ${ }^{46}$

Não é à toa que a psicanálise já foi chamada de "psicologia das profundezas". Esta denominação muito tem a ver com a forma pelo qual um ato psíquico inconsciente pode fazer parte da consciência. $O$ processo pelo qual um ato psíquico passa do inconsciente (Ics) para o consciente (Cs) é balizado pela barreira da censura. Se um pensamento

44 FREUD, Sigmund. "O inconsciente". In.: Introdução ao narcisismo: ensaio de metapsicologia e outros textos. Tradução e notas: Paulo César de Souza. São Paulo: Companhia das letras, 2010, pp. 101 - 102.

45 Idem, p. 101.

46 Idem, p. 101. 
inconsciente é vetado pelo exame da censura, este conteúdo é reprimido e continua inconsciente. Caso ele consiga passar pela censura, este pensamento não é diretamente consciente, mas capaz de consciência, ou seja, fica num estado de pré-consciência ( $P c s)$. A partir daí, um conteúdo pré-consciente pode passar por uma segunda censura e se tornar consciente. A repressão é um processo que se encontra no limite entre Ics e Pcs (Cs). "Por enquanto basta ter em mente que o sistema Pcs partilha das propriedades do sistema Cs e que a censura rigorosa cumpre seu papel na passagem do Ics para o Pcs." 47

Podemos perceber uma confluência de elementos no Ics que fazem parte das suas características. Lá se encontram os representantes das pulsões que procuram descarregar a energia sexual pela realização de desejo. As pulsões convivem mutuamente, não se contradizem, mesmo sendo opostos. Os processos inconscientes são constituídos pela atemporalidade. Não existe linha cronológica no Ics. Ele não é ordenado pelo tempo. No Ics não se leva em conta a realidade. Ele é regido pelo princípio do prazer e seu percurso depende da intensidade e de cumprir as demandas do prazer-desprazer. Os processos inconscientes nos são mais cognoscíveis através do sonho e das neuroses. No sonho, a censura e o trabalho da repressão são colocados em uma forma de rebaixamento, o que permite que os processos inconscientes se manifestem em forma de sonho. "Neste sistema não há negação, não há dúvidas nem graus de certeza. Tudo isso é trazido pelo trabalho da censura entre Ics e Pcs. A negação é um substituto da repressão em nível mais alto.” 48

Estas características do Ics podemos encontrar nas imagens de Um cão andalur. A atemporalidade é o tempo do filme. Ele não tem uma sequência cronológica das cenas e de seus desencadeamentos. Além disso, várias telas nos apresentam cortes que não se sucedem cronologicamente tais como "Era uma vez", "Oito anos depois", "Pelas três da manhã", "Dezesseis anos antes", "Na primavera". O filme forma e transforma o tempo como no sonho. Não é à toa que, ao vermos este filme, temos a impressão de estarmos assistindo um sonho através do cinema. Além destes cortes temporais que não se sucedem cronologicamente, uma forma de poder perceber o Ics é pelo sonho, pois neste o trabalho da censura e da repressão não se dá na sua integridade.

No filme, podemos perceber a confluência das pulsões que estão prontas para descarregar suas energias através do desejo. Vemos o desejo da morte do outro na cena em que o casal assiste o atropelamento da mulher segurando a caixa. Depois percebemos o desejo sexual, logo após ver o atropelamento do outro, o homem avança para a mulher, querendo agarrá-la a todo custo. Podemos perceber o desejo de matar quando os livros se 
transformam em armas e o personagem atira com muita satisfação. Podemos perceber a agressividade do casal ao discutirem, ao se instigarem. Também podemos constatar no final do filme o desejo de amor, quando a mulher deixa o homem em casa, abre uma porta e se encontra na praia com o mesmo homem, mas ele está diferente, os olhares são outros. Ela é bem mais carinhosa e eles passeiam pela praia abraçados.

Tanto o Ics quanto o filme se regem pelo princípio do prazer e não pela realidade. É possível notar esta característica pelo desenrolar das cenas e dos atos dos personagens. Uma mulher desce as escadas para ajudar o rapaz que acaba de cair de bicicleta e que bateu com a cabeça na calçada. Ela se aproxima e retorna para o quarto com uma caixa, onde se encontram algumas peças de vestuário do homem. Uma mão decepada que está na rua é guardada dentro de uma caixinha de madeira. A personagem que encontrou a mão segura a caixa como se fosse um presente. A mulher tranca a mão do homem na porta, da mão começa a sair formigas, a mão se fecha. A mulher não prende mais a mão dele e encontra o mesmo homem no quarto, deitado na cama. Em outra cena, a personagem abre a porta para outro cômodo e já encontra a praia. Todas essas imagens fazem parte do princípio do prazer por serem descontínuas, por não apresentarem conexão com uma realidade.

E a repressão, que é a fronteira e a barreira entre o inconsciente e o pré-consciente, não fica despercebida neste filme que nos mostra tantas formas do Ics. Percebo a repressão na cena final do filme, depois da citação "Na primavera", quando o casal aparece enterrado nas areias da praia. Para mim, esta cena apresenta todo o trabalho da repressão ao não permitir que um conteúdo inconsciente possa ser capaz de consciência. A repressão demonstra a sua força pela censura e enterra esse conteúdo no inconsciente, como se de lá ele jamais pudesse sair, nem com a chegada da primavera. 


\section{Referências}

BENJAMIN, Walter. "O Surrealismo: o último instantâneo da inteligência européia" In: Magia e Técnica, Arte e Política. São Paulo: Brasiliense, 1994.

BRETON, Andre. Manifesto Surrealista. 1924.

BUÑUEL, Luis. Escritos de Luis Buñuel. Paginas de Espuma: Espanha, 2000.

CHÉNIEUX-GENDRON, Jacqueline. O Surrealismo. Tradução de Mário Laranjeira. São Paulo: Martins Fontes, 1992.

FREUD, Sigmund. "O estranho" In: História de uma neurose infantil e outros trabalhos. Volume 17. Imago: Rio de Janeiro, 1969.

. "O inconsciente" in Introdução ao narcisismo: ensaio de metapsicologia e outros textos. Tradução e notas: Paulo César de Souza. São Paulo: Companhia das Letras, 2010.

JAY, Martin. "The disenchantment of the eye: Bataille and the Surrealists" in Downcast Eyes: the denigration of vision in twentieth century, 1993.

ROUDINESCO, Elizabeth; PLON, Michel. Dicionário de Psicanálise, Rio de Janeiro: Jorge Zahar, 1998.

O CÃO ANDALUZ. Direção: Luis Buñuel.1929. DVD (16 min). 